\title{
Six generations of ill-used children in a Huntington's pedigree
}

\author{
J. E. Oliver \\ M.B. (Lond.), D.P.M. \\ Senior Registrar, \\ Borocourt Hospital, Near Reading, Berks
}

\author{
K. E. Dewhurst \\ D.Phil. (Oxon.), D.P.M. \\ Research Psychiatrist, \\ Littlemore Hospital, Oxford
}

\section{Summary}

This Huntington's pedigree of six generations illustrates the interaction of environmental and genetic factors causing prolonged suffering to children reared in such families.

This pedigree is representative of many others studied in depth involving at least 425 families. In general, children reared in these families later manifest subtle anti-social tendencies. Even when these children do not carry the specific gene themselves, the consequences of their upbringing results in psychiatric and anti-social sequelae in their adult lives. These are most serious where both parents are psychotic. In such cases the third generation is almost invariably crippled by alcoholism, chronic neurosis or psychopathy, initiating 'problem families' in subsequent generations.

Attention is drawn to recent legislation concerning family planning and therapeutic abortion which are still, unfortunately, the only means of preventing the devastating hereditary consequences of this disease.

\section{Introduction}

In this family pedigree the majority of children from at least four of the six generations were subjected to both active cruelty and passive neglect. Detailed surveillance over five generations has been possible as members of this Northamptonshire pedigree were followed on account of the transmission of Huntington's disease (Pleydell, 1954). In this pedigree (Northants Pedigree No. 15, Oliver, 1969; and Dewhurst, Oliver \& McKnight, 1969), the illness in all affected members began with irritability and insidious deterioration of personality, often accompanied by overtly anti-social behaviour. In most cases the prodromal phase of the illness is prolonged, starting in the childbearing years.

Although half the children of a Huntington's family are at risk, the pernicious effects of the disease are not confined to those carrying the gene, or to others subjected to maltreatment from a dementing, psychotic parent. Wherever they could be followed up, even those lines which escaped the deleterious gene were characterized by neurosis, fecklessness, neglect of children, psychopathy and problem families, for two or more generations.

Brutal home environments and the gloomy spectre of hereditary madness often lead young adults and teenagers to form unsatisfactory sexual partnerships, frequently with resultant illegitimacies. Early marriages, destined to desolate failure, are frequently contracted with young partners either from problem families or with others affected with various forms of mental illness.

\section{Pedigree study (see Fig. 1) \\ Generation I}

The immediate antecedents of subject I, No. 1 originated from south Northamptonshire and Buckinghamshire. She came from a 'hard, bad background', and died in the county asylum of Huntington's disease.

\section{Generation II (No. 2)}

'... always in rages and tempers, until she went mad, like her mother. She was vicious and cruel to all her children', and 'did something vicious to E.L.' (wife of III 2). She died of Huntington's disease.

\section{Generation III}

Initially only three of this generation were revealed by members of generation IV, although hospital notes eventually brought to light four more 'skeletons in the family cupboard'. The notes were frequently contradictory regarding the birth-order of these siblings, their parentage (some illegitimate) and the mental hospitals or other institutions to which they had been admitted.

III, No. 1. Died 64 years. No legitimate children.

III, No. 2. Onset of Huntington's chorea at least by the age of 43 , died aged 55 . He married a severely neurotic woman, with a family history of manicdepressive psychosis, having a sister and several other relatives in the county asylum. Before the clear onset of Huntington's chorea, he (III 2) was out of work, depressed, irritable, and under the impression that his wife was being persistently 


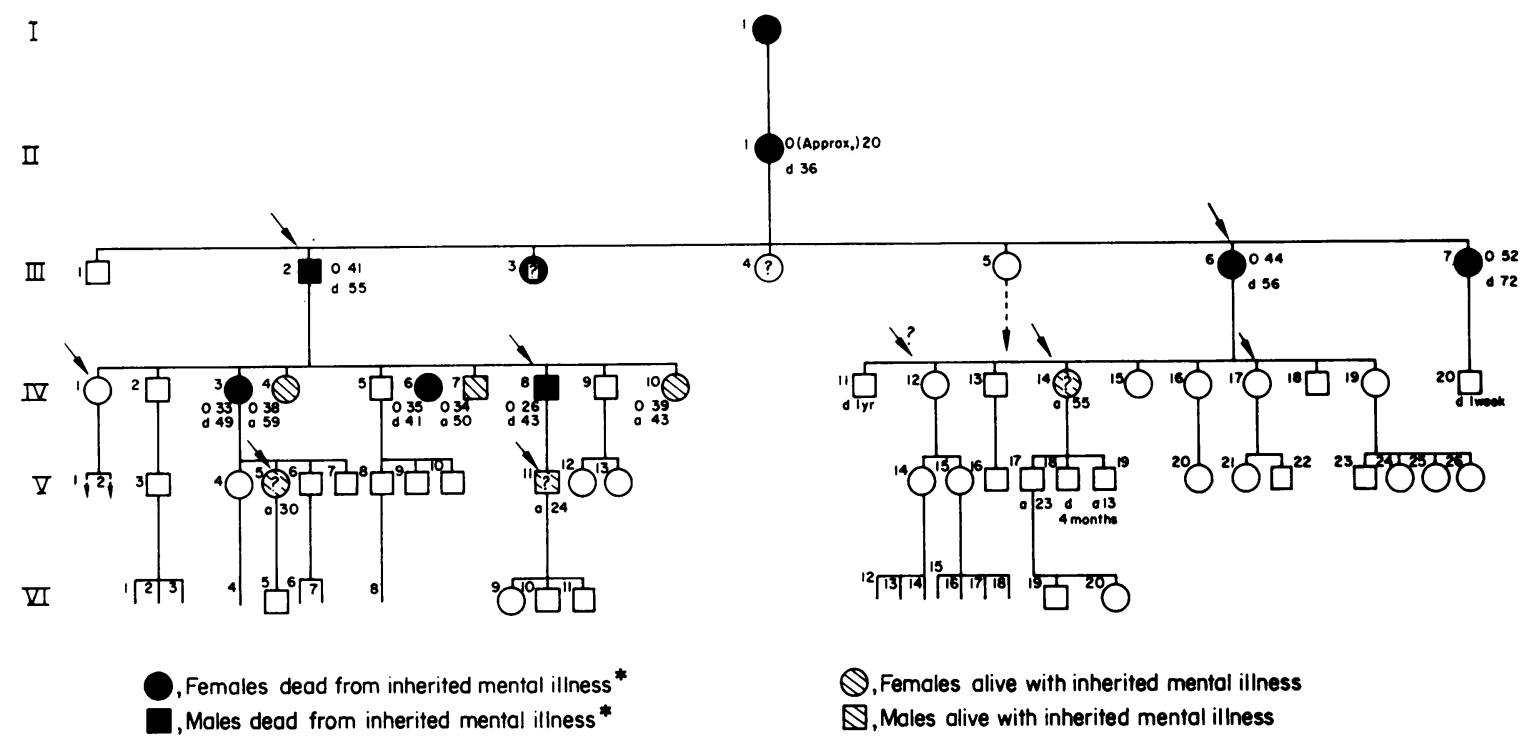

FIG. 1. Pedigree. O, Age at onset; d, age at death; a, present age. Parents deserted, divorced or married to a mentally ill or psychopathic partner are indicated by an oblique arrow. ${ }^{*}$ Huntington's chorea. Other mental illnesses are given in the text.

unfaithful to him. Apart from irrational aggressive outbursts against his wife and young children, he appeared to have little interest in his family. His children were frequently farmed out to mentally sick relatives.

III, Nos. 3, 4 and 5. The relatives in generation IV were generally unwilling to discuss these three sisters, one of whom favoured a feckless existence in London with casual prostitution, starting a line of problem families, delinquents and gaolbirds. Of the remaining two sisters, one possibly suffered from Huntington's disease, and both had spells in London mental hospitals. The number of their descendants is not known.

III, No. 6. After a long period of depression, irritability and social decline, this sister became confused and later developed the characteristic features of Huntington's chorea. Her family of nine suffered her inadequacies and outbursts of rage, but were subjected to even more active cruelties from her alcoholic husband. The early paranoid, sadistic characteristics of his behaviour later evolved into a typical paranoid schizophrenia.

III, No. 7. Irritability, self neglect and episodes of self-starvation heralded the onset of Huntington's chorea. Her one child died shortly after birth. She outlived her husband, and died in the county asylum.

\section{Generation IV}

Cruelty, abandonment and neglect in early childhood have left an indelible mark on all subjects in this generation. Subjects 1-19 had little or no love or parental affection and had few (if any) healthy relatives to cushion them from cruelty ando neglect.

$I V$, No. 1. Illegitimate, with two or more illegitimate children herself. The rest of her generation initially denied her existence, but, when pressed claimed she was 'too shameful to be considered a member of the family'!

$I V$, No. 2. 'Mentally getting dull and slow'. Self-centred and miserable, nurturing his duodenal ulcer with excessive quantities of alcohol.

$I V$, No. 3. Particularly brutal to her young children, and committing violence on her passive husband. This behaviour (antedating the characteristic features of Huntington's chorea) necessitated her compulsory detention in a mental hospital.

$I V$, Nos. 4, 6, 7 and 10. These subjects had no children. For each of them, the prodromal phase of Huntington's disease, with insidious dementia, irritability, loss of self-control and deterioration of personality was intimately coloured by their traumatic childhood experiences. Subject IV 6, for instance, frequently physically attacked her mother, making incessant vituperative accusations against both her and her dead father.

$I V$, No. 5. Reported to be a heavy evening and week-end drinker, verging on chronic alcoholism. There are doubts as to the future of his marriage.

$I V$, No. 8. Thieving, worklessness, physical violence, headaches and insomnia antedated the more florid features of Huntington's disease. His wife 
left him, abandoning the child $(\mathrm{V}$, No. 11) to the care of unwilling grandparents, who in turn farmed him out to a psychotic aunt. The wife herself had a bitter and sadistic temperament. This is exemplified by visits to her son (V, No. 11) during his compulsory detention either in gaols or special hospitals, at which times she discussed either his wife's infidelities or details of his father's perversions.

$I V, N o .9$. Appeared to be relatively normal and gave a helpful account of certain aspects of the family background.

$I V$, No. 11. Died in doubtful circumstances before he was 1 year old.

$I V$, Nos. 12, 13, 17 and 19. These four subjects show neurotic features of variable severity, accompanied by serious marital troubles in three of them. There is no way of ascertaining, however, whether some of the symptomatology is part of the early prodromata of Huntington's disease rather than arising from chronic maltreatment as children. IV 17 has had much psychiatric attention, with recurrent marital crises. She attempted to emigrate but instead was admitted to mental hospital.

$I V$, No. 14. Probably this subject is in the early stages of Huntington's disease. She has been, for a long time, an unstable drifter, separated from her husband. She has little contact with her eldest illegitimate child, her second child died at $4 \frac{1}{2}$ months and her third (illegitimate) child lives with her. At first irritable and quarrelsome, she now alternates between paranoid suspiciousness and fatuous euphoria. She is vague, evasive, slovenly and inconsistent. Her 13-year-old son reacts to his mother by being 'a law unto himself'.

$I V$, Nos. 15 and 16. There are few details available about these two sisters, one of whom (IV 15) died of 'a stroke' at the age of 47.

$I V, N o$. 18. This man, once a builder, is suffering total disintegration of his personality as a result of chronic alcoholism.

\section{Generation $V$}

Many of this generation are children, and the parents of others have left Northants. Several of them (such as V 12 and 13, and 23-26) had clearly not suffered the physical maltreatment of those children in generations I-IV. Others, such as V 19-22 (and the children of those alcoholics in generation IV), have been suffering psychologically as a result of the gross neuroses and disturbances of personality in their parents. V 1 and 2 are known to have been in trouble, but are untraceable now.

$V$, Nos. 4, 5, 6 and 7 were all 'very neglected in childhood' (Psychiatric case notes of V 4). V 5, so far, has one illegitimate child, and is "highly strung and odd' (irritability, apathy and depression). V 6 'likes pubs too much' and is under psychiatric care, likewise his fiancée.

$V, N o .11$. This man has probably suffered physical and mental sadism as a child, as well as gross neglect from parents and parent-substitutes. He has twice been in Broadmoor following episodes of violence, and has a long criminal record with brutal assaults against his wife and the police. He may well be in the early stages of Huntington's disease. His wife, a pathological liar, has repeatedly abandoned her children in callous circumstances in order to devote more time to prostitution.

$V$, Nos. 17-19have suffered disruptions, violence and bizarre situations as a result of the whims and impulses of their feckless mother and her strange associates.

\section{Generation VI}

Fourteen of these children remain in Northamptonshire. Ten of them are relatively fortunate in having at least one mentally healthy parent. VI 5 , the illegitimate son of $\mathrm{V} 5$ is partly protected from the vagaries of his mother by an elderly grandfather.

The three children of V 11, subjects VI 9,10 and 11 are in care having been deserted by their mother on four occasions, and later abandoned by other relatives. The National Society for the Prevention of Cruelty to Children have been involved, and the children have frequently been in an advanced state of neglect. Their mother, father and grandparents all are untruthful and ill-intentioned, lying with effortless ease. Thus the efforts of the Northampton Children's Department are greatly hindered in their endeavours to provide care for these three disturbed youngsters, the eldest of whom is 5 .

\section{Discussion and conclusions}

Before the N.H.S. Family Planning Act (Hansard, 1967) and the Abortion Act of 1968, preventive medicine in this field of psychiatry was totally ineffectual. In this context the R.M.P.A. has made recommendations concerning the aborting of unwanted pregnancies (R.M.P.A. Memorandum, 1966) but has only paid cursory attention to family planning and the implications of the 1967 Family Planning Act. Subjects I 1; II 1; III 2, 6; IV 3, 6, 8 and 14 (and possibly V 5 and 11) illustrate that the prodromal phase of Huntington's disease, with its concomitant of a heightened degree of irresponsibility, poses special problems in birth control and preventive psychiatry. These considerations are discussed in general by Whittier (1968) and Hans \& Gilmore (1968) and for the Northants pedigrees in particular by Pleydell (1968) and Oliver (1969).

The pedigree described here is typical of twentyfive others involving at least 425 families. Very frequently all the children from these families show anti-social tendencies in adult life. A high deathrate among the nineteen Northamptonshire choreic 
families has been reported by Oliver (1969). Furthermore, specific examples of infanticide, brain injury, incest, incestuous sodomy, sadism and other perversions practised on children in such families has been reported in detail elsewhere (Dewhurst et al., 1969; Oliver, 1969).

\section{References}

Dewhurst, K.E., Oliver, J.E. \& McKnight, A.L. (1969) Familial Characteristics of Huntington's Disease. (In press).
(Family Planning) Bill (N.H.S.) (1967) Hansard, 741, No. 146.

HaNS, M.B. \& Gilmore, T.H. (1968) Social aspects of Huntington's chorea. Brit. J. Psychiat. 114, 93.

OLIver, J.E. (1969) Huntington's chorea in Northamptonshire. Brit. J. Psychiat. (In press).

Pleydell, M.J. (1954) Huntington's chorea in Northamptonshire. Brit. med. J. 2, 1121.

Pleydell, M.J. (1968) Indications for termination of pregnancy. Brit. med. J. 1, 376.

R.M.P.A. Memorandum on Therapeutic Abortion (1966) Brit. J. Psychiat. 112, 1071.

WhitTIER, J.R. (1968) Treatment of Huntington's disease. Mod. Treatm. 5, 332 